\title{
Youtubers e juventude: uma análise dos vídeos mais populares e suas implicações na saúde mental
}

\section{Youtubers and youth: an analysis of the most popular videos and their consequences for the mental health}

\section{Youtubers y jóvenes: un análisis de los videos más populares y sus consecuencias para la salud mental}

\author{
Catherine Menegaldi Silva $a^{1, a}$ \\ catherinemenegaldi@gmail.com | https://orcid.org/0000-0001-5386-0205
}

Raelly Beatriz Gomes Benetti ${ }^{2, b}$

raellybeatriz@gmail.com | https://orcid.org/0000-0002-0615-3847

Camila Cortellete $e^{1, c}$

camilacortellete@hotmail.com | https://orcid.org/0000-0001-5065-5556

Tiago Franklin Rodrigues Lucena ${ }^{3, d}$

tiagofranklin@gmail.com | https://orcid.org/0000-0002-0154-7417

Rute Grossi-Milani ${ }^{1, e}$

rute.milani@unicesumar.edu.br | https://orcid.org/0000-0003-2918-1266

\footnotetext{
${ }^{1}$ Universidade Cesumar, Pós-Graduação em Promoção da Saúde. Maringá, PR, Brasil.

${ }^{2}$ Universidade Estadual de Maringá, Departamento de Psicologia. Maringá, PR, Brasil.

${ }^{3}$ Universidade Estadual de Maringá, Departamento de Fundamentos da Educação. Maringá, PR, Brasil.

a Mestrado em Promoção da Saúde pela Universidade Cesumar.

b Graduada em Psicologia pela Universidade Cesumar.

c Mestrado em Promoção da Saúde pela Universidade Cesumar.

d Doutorado em Arte e Tecnologia pela Universidade de Brasília.

e Doutorado em Medicina pela Universidade de São Paulo.
}

\section{RESUMO}

Estudo de caráter exploratório que tem como objetivo analisar as temáticas abordadas em vídeos produzidos por youtubers brasileiros. Foram levantados os 10 principais canais para o público jovem na plataforma de vídeos YouTube, de 19 de março de 2019 até o8 de abril de 2019, criados e apresentados pelos chamados youtubers. Após seleção e análise foram obtidas as seguintes categorias: cultura tecnológica, relações familiares e sexualidade. Os vídeos possuem expressivo número de visualizações e abordam temáticas de interesse do público jovem, porém revelam carência de fundamentos teórico-científicos sobre as implicações que têm em sua saúde mental. Conclui-se que é preciso inserir os pais e os jovens em discussões de educação digital, de modo a conscientizá-los dos possíveis riscos provocados por alguns conteúdos e a dialogarem a respeito do uso consciente e saudável da tecnologia.

Palavras-chave: Adolescência; Acesso à internet; Comportamento; Promoção da saúde; Psicologia. 


\title{
ABSTRACT
}

Exploratory study aiming to analyse themes - addressed in videos produced by Brazilian Youtubers - focusing on mental health. The ten most-viewed channels aimed at teen audience on the video platform YouTube from March 19, 2019 to April 8, 2019 created and presented by the so-called Youtubers were searched out. After selecting and analysing, the following categories were obtained: technological culture, family relationships and sexuality. These videos have a significant number of users and deal with topics of interest to the young audience, nevertheless they have no scientific basis concerning the possible consequences of their contents for the mental health of their public. It was concluded that it is necessary parents and young people become involved with discussions on digital education, in order to have aware of the possible risks produced by some contents and to dialogue about the conscious and healthy use of technology.

Keywords: Adolescence; Internet access; Behavior; Health promotion; Psychology.

\section{RESUMEN}

Este artículo presenta un estudio exploratório con el objetivo de analizar los temas tratados en vídeos producidos por youtubers brasileños. Fueron rastreados los 10 principales canales dirigidos a la audiencia adolescente en la plataforma YouTube, desde 19 de marzo de 2019 hasta 8 de abril de 2019, creados y presentados por los llamados youtubers. Después de la selección y del análisis, se obtuvieron las categorías siguientes: cultura tecnológica, relaciones familiares y sexualidad. Los vídeos tienen un número significativo de visualizaciones y se ocupan de temas de interés del público joven, pero no tienen fundamentos científicos acerca de las implicaciones de su contenido para ese público. Ha sido concluido que es necesario que los padres y los jóvenes se reúnan en discusiones sobre educación digital, a fin de generar consciencia acerca de los posibles riesgos originados de algunos contenidos y diálogo sobre el uso consciente y saludable de la tecnologia.

Palabras clave: Adolescencia; Acceso a internet; Conducta; Promoción de la salud; Psicología.

\begin{abstract}
Contribuição dos autores:
Concepção e desenho do estudo: Catherine Menegaldi Silva, Camila Cortellete, Tiago Franklin Rodrigues Lucena, Rute Grossi-Milani. Aquisição, análise ou interpretação dos dados: Catherine Menegaldi Silva, Raelly Beatriz Benetti, Camila Cortellete, Tiago Franklin Rodrigues Lucena, Rute Grossi-Milani.

Redação do manuscrito: Catherine Menegaldi Silva, Raelly Beatriz Benetti, Camila Cortellete, Tiago Franklin Rodrigues Lucena, Rute Grossi-Milani.

Revisão crítica do conteúdo intelectual: Tiago Franklin Rodrigues Lucena, Rute Grossi-Milani.
\end{abstract}

Declaração de conflito de interesses: não há.

Fontes de financiamento: Conselho Nacional de Desenvolvimento Científico e Tecnológico (CNPq), Coordenação de Aperfeiçoamento de Pessoal de Nível Superior (Capes) e Instituto Cesumar de Ciência, Tecnologia e Inovação (Iceti).

Considerações éticas: não há.

Agradecimentos/Contribuições adicionais: Programa Institucional de Bolsas de Iniciação Científica Pibic/CNPq-IcetiUniCesumar.

Histórico do artigo: submetido: 5 out. 2020 | aceito: 6 mar. 2021 | publicado: 30 jun. 2021.

Apresentação anterior: não houve.

Licença CC BY-NC atribuição não comercial. Com essa licença é permitido acessar, baixar (download), copiar, imprimir, compartilhar, reutilizar e distribuir os artigos, desde que para uso não comercial e com a citação da fonte, conferindo os devidos créditos de autoria e menção à Reciis. Nesses casos, nenhuma permissão é necessária por parte dos autores ou dos editores. 


\section{INTRODUÇÃO}

O consumo de vídeos online é uma tendência observada na última década no Brasil e no mundo (MARINHO, 2018). A plataforma YouTube, da empresa Google, aparece como a preferida para o consumo de conteúdo em formato audiovisual com vídeos de diversos temas, gêneros e nacionalidades (PRIOSTE, 2016). Nesse contexto, destaca-se a presença dos chamados youtubers, que são pessoas comuns e que, via de regra, apresentam características como autenticidade, inteligência e senso de humor, envolvendo os espectadores em suas narrativas e causando sensação de proximidade a quem assiste aos seus vídeos, fomentando a identificação com a personagem interpretada pelo dono do canal (YOUTUBERS..., 2016; MARINHO, 2018. São, portanto, indivíduos com alto poder mobilizador e formadores de opinião.

O impacto dos youtubers naqueles que consomem seus conteúdos é tão significativo que foi retratado em diversos estudos, como o de Carvalho, Marôpo e Pereira (2020), que abordaram o poder mercadológico envolvido. Os autores salientaram que, além de representarem fonte de entretenimento e informação, os conteúdos produzidos têm efeitos sobre a percepção e o comportamento dos sujeitos que os acompanham, razão pela qual muitos são chamados de influenciadores digitais. As repercussões se dão de forma diversa nos espectadores, algo ratificado por Vingilis et al. (2018), que constataram a influência de vídeos do YouTube a respeito de corridas de automóveis, ou de outras competições do mesmo gênero, principalmente em jovens do sexo masculino, levando-os a comportamentos de risco e, por Deslandes e Coutinho (2020), que verificaram a influência de algumas plataformas da internet que provocam o aumento da incidência de atos autolesivos em crianças e adolescentes.

Quando se trata do público adolescente, essa influência é ainda maior, por usarem figuras e elementos comuns do cotidiano jovem, tais como brincadeiras, situações violentas, sexuais ou que geram raiva (COSTA, 2020). Ocorre uma intensa identificação com os youtubers, que podem ser percebidos como pessoas que os "entendem melhor que os próprios amigos" (CARVALHO; MARÔPO; PEREIRA, 2020, p. 43). Neste sentido, é importante notar que entre o público que mais consome vídeos do Youtube no Brasil estão jovens com idade entre 15 e 24 anos, representando 22,4\% dos usuários (PRIOSTE, 2016; OS YOUTUBERS..., 2016). Isso deve ser levado em consideração ao pensar nos assuntos que são abordados nos vídeos disponibilizados na plataforma digital, nas mensagens que carregam e nos impactos sobre o espectador.

A adolescência é um período singular do desenvolvimento humano, em que se dá a transição da infância para a vida adulta, por volta dos 12 aos 18 anos, segundo o Estatuto da Criança e do Adolescente (BRASIL, 2010). É influenciada tanto pela história de vida, quanto pela rede social e cultural na qual o sujeito está inserido (GOMES, 2018). Neste sentido, percebe-se o poder de persuasão dos youtubers na vida dos adolescentes, visto que são expostos a conteúdos pouco mediados e filtrados no que diz respeito à relevância pedagógica e/ou segurança. Esse elemento levantou o debate em diferentes setores da sociedade, preocupados com a provável influência dos youtubers no rendimento escolar, no suicídio e no comportamento agressivo e político (KNIGHT; INTZANDT; MACDOUGALL; SAUNDERS, 2015; RATWATTE; MATTACOLA, 2019). De fato, alguns youtubers são elevados à categoria de ídolos dos jovens (YOUTUBERS..., 2016), ao publicarem vídeos com aspecto amador, falando diretamente para a câmera, convidando o público a conhecer suas vidas, casa e rotina (MARINHO, 2018).

$\mathrm{O}$ acesso irrestrito à internet, muitas vezes sem qualquer controle dos pais, acompanhado do sucesso alcançado pelo YouTube, precisa ser levado em consideração, uma vez que o adolescente se encontra em um estado de vulnerabilidade emocional e cognitiva (SANTOS; GOMES; TEIXEIRA; ROEVER et al., 2017). O YouTube também constitui uma rede social na qual as interações por meio dos 'ikes', 'dislikes' e comentários estimulam as produções de novos conteúdos. Com essa interação, os espectadores transmitem 
como gostariam de ter sua identidade, cultura e vivência representadas e, ao seguir por este caminho, youtubers alimentam a identificação e o fascínio, enquanto os jovens tendem a repetir os hábitos, consumos, estilos e tendências dessas figuras (COSTA, 2020; BERNARDAZZI, 2016).

Nesse sentido, a construção da subjetividade do jovem é perpassada por informações advindas das redes sociais online (FRANÇA, 2016). Em decorrência da influência subjetiva exercida pelos youtubers e do uso que os jovens fazem da plataforma, ampliou-se a atenção dada a este fenômeno por parte de familiares, profissionais da saúde e pesquisadores sociais, devido à necessidade de entender as implicações que têm determinados vídeos na saúde mental de seus usuários (COSTA, 2020; LUPTON, 2021). O presente estudo visa analisar as temáticas abordadas nos vídeos produzidos por youtubers brasileiros com foco na saúde mental dos adolescentes. A pesquisa abrange contribuições teóricas da intersecção entre netnografia (CARVALHO; MARÔPO; PEREIRA, 2020) e psicologia, a fim de contribuir para o entendimento das possíveis implicações no comportamento e na saúde mental de alguns jovens.

\section{METODOLOGIA}

O presente estudo caracteriza-se como exploratório, com análise de conteúdo (BARDIN, 2016) de vídeos postados no site YouTube por usuários brasileiros. Identificaram-se os dez principais youtubers do Brasil e seus vídeos mais visualizados, bem como as temáticas nesses trabalhadas. Para isso, foi necessário definir os maiores canais do YouTube, por meio de um ranking divulgado no website SocialBlade (c2018). O site, que inclusive possui selo de certificação do YouTube, utiliza os bancos de dados públicos fornecidos pelo YouTube, Twitch, Instagram, Twitter e, usando tecnologia avançada, analisa estatisticamente os usuários dessas mídias.

Desse modo, na aba Top Lists no website, foi empregado primeiramente o filtro YouTube, para posteriormente selecionar a opção Top 250 from Brazil, sendo disponibilizada uma listagem dos 250 canais do YouTube com maior número de seguidores. Neste sentido, elegeu-se como critério de inclusão os canais brasileiros mais visualizados pelo público jovem, contendo a figura do youtuber. Foram excluídos os canais de conteúdo musical, dança e coreografia (3), infantis e com personagens animados (6), esquetes (2) e canais com última publicação há mais de dois meses (1), ou seja, antes de janeiro de 2019. Posteriormente, foram elencados os dez canais com maior número de seguidores.

Para identificar os vídeos mais visualizados de cada youtuber, utilizou-se a plataforma do YouTube. Primeiramente, acessou-se cada canal, selecionou-se a aba Vídeos, que apresenta todos aqueles já publicados pelo youtuber, e aplicou-se o filtro favoritos, resultando na apresentação dos vídeos organizados por número de visualizações. Em seguida, selecionaram-se os três vídeos mais visualizados, nos anos de 2017 a 2019 de cada canal, totalizando assim 30 vídeos (Quadro 1). 


\section{Quadro 1 - Vídeos mais visualizados por tema}

\begin{tabular}{|c|c|c|c|}
\hline Canal & Vídeos mais visualizados & Visualizações & Temática \\
\hline \multirow{3}{*}{ Whindersson Nunes } & Na sua cara | Paródia & 57.619 .038 & Relações familiares \\
\hline & Paródia / Haikaiss & 53.975 .338 & Cultura tecnológica \\
\hline & Eu cansei de ser pobre | Paródia Ed Sheeran & 49.873 .812 & Vulnerabilidades \\
\hline \multirow{3}{*}{ Felipe Neto } & Rebuliço - Paródia Despacito & 49.901 .351 & Cultura tecnológica \\
\hline & Provando doces asiáticos estranhos [+13] & 25.930 .988 & Competições e desafios \\
\hline & Meu melhor amigo - Luccas Neto & 24.045 .690 & $\begin{array}{l}\text { Relacionamentos } \\
\text { interpessoais }\end{array}$ \\
\hline \multirow{3}{*}{ Você Sabia? } & 10 pessoas que morreram tirando selfie & 17.382 .906 & Cultura tecnológica \\
\hline & $\begin{array}{l}\text { Veja por que a Austrália é o país mais } \\
\text { perigoso do mundo }\end{array}$ & 14.723 .666 & Curiosidades \\
\hline & $\begin{array}{l}\text { Veja como sobrevivem no lugar mais quente } \\
\text { do mundo }\end{array}$ & 12.125 .156 & Curiosidades \\
\hline \multirow{3}{*}{ Rezendeevil } & Sacrifício | paródia Despacito & 14.036 .982 & Cultura tecnológica \\
\hline & $\begin{array}{l}\text { Minecraft vs Bob esponja: giga bob esponja } \\
\text { vs rezende !!! }\end{array}$ & 12.897 .990 & Competições e desafios \\
\hline & Os beijos mais estranhos com namorada!! & 12.333 .755 & Sexualidade \\
\hline \multirow{3}{*}{ Canal Canalha } & Pequenas atitudes irritantes de mãe & 17.607.017 & Relações familiares \\
\hline & Despedido - paródia despacito & 13.589 .233 & Sexualidade \\
\hline & Gemidão do zap! Paródia Pabllo Vittar - K.O. & 12.871 .503 & Sexualidade \\
\hline \multirow{3}{*}{ Am3nic } & $\begin{array}{l}\text { Musica minecraft saphira - animation feat. } \\
\text { Tauz }\end{array}$ & 7.551 .121 & $\begin{array}{l}\text { Relacionamentos } \\
\text { Interpessoais }\end{array}$ \\
\hline & Tentei gravar 1 hora de vlog & 7.135.129 & Curiosidades \\
\hline & Interesseira da porsche panamera existe? & 6.036 .628 & Sexualidade \\
\hline \multirow{3}{*}{ Canal Nostalgia } & Retrospectiva animada 2017 & 9.017 .776 & Curiosidades \\
\hline & A terra é plana? Com Leon e Nilce & 6.238 .728 & Conhecimentos Gerais \\
\hline & $\begin{array}{l}\text { A História de quando fui traído e ainda } \\
\text { filmaram! }\end{array}$ & 6.114 .528 & Sexualidade \\
\hline \multirow{3}{*}{ Manual do Mundo } & Como fazer um hand spinner & 8.683 .899 & Curiosidades \\
\hline & Como é feita a goma de mascar \#Boravê & 8.143 .805 & Curiosidades \\
\hline & $\begin{array}{l}\text { Como transformar papel alumínio em uma } \\
\text { bola de metal }\end{array}$ & 7.573 .462 & Curiosidades \\
\hline \multirow{3}{*}{ Dani Russo TV } & Playlist de funk pesadona 4 & 24.747 .433 & Curiosidades \\
\hline & $\begin{array}{l}\text { Perdi minha virgindade com um cara do } \\
\text { tinder? }\end{array}$ & 19.591 .467 & Sexualidade \\
\hline & Apanhei da minha mãe & 13.009 .768 & Relações familiares \\
\hline \multirow{3}{*}{ Renato Garcia } & $\begin{array}{l}\text { A Lenda da casa amaldiçoada - Caçadores de } \\
\text { Lendas }\end{array}$ & 12.174 .136 & Competição e Desafios \\
\hline & $\begin{array}{l}\text { Fomos atacado no hospital abandonado de } \\
\text { noite }\end{array}$ & 10.976 .659 & Competição e desafios \\
\hline & $\begin{array}{l}\text { Ficou possuído no velho satânico - Caçadores } \\
\text { de Lendas }\end{array}$ & 8.138 .535 & Competição e desafios \\
\hline
\end{tabular}

Fonte: elaboração dos autores.

Por fim, para classificar as temáticas abordadas, os vídeos foram assistidos, classificados, avaliados e tabulados utilizando como ferramenta o Excel 2016. Também se empregou a técnica de análise de conteúdo de Bardin (2016), possibilitando a identificação das temáticas presentes em cada um deles, tanto nos 
recursos audiovisuais, quanto nos comentários de cada publicação e permitindo, assim, relacionar essas descobertas com as possíveis implicações no comportamento e na saúde mental de adolescentes.

\section{RESULTADOS E DISCUSSÕES}

A seguir será apresentada a listagem dos principais canais do YouTube brasileiro apresentados por youtubers e visualizados pelo público jovem (Figura 1), contendo o número de inscritos, o número de visualizações e a quantidade de vídeos já publicados em cada canal de 19 de março de 2019 a 8 de abril de 2019.

\begin{tabular}{|c|c|c|c|c|}
\hline $\begin{array}{c}\text { Whindersson } \\
\text { Nunes }\end{array}$ & Felipe Neto & Você sabia? & Rezendeevil & $\begin{array}{c}\text { Canal } \\
\text { Canalha }\end{array}$ \\
\hline $\begin{array}{l}\text { Inscritos } \\
35.109 .540\end{array}$ & $\begin{array}{l}\text { Inscritos } \\
31.339 .751\end{array}$ & $\begin{array}{l}\text { Inscritos } \\
23.081 .064\end{array}$ & $\begin{array}{l}\text { Inscritos } \\
22.749 .655\end{array}$ & $\begin{array}{l}\text { Inscritos } \\
18.279 .054\end{array}$ \\
\hline $\begin{array}{l}\text { Visualizaçōes } \\
2.858 .442 .997\end{array}$ & $\begin{array}{l}\text { Visualizaçöes } \\
6.312 .245 .179\end{array}$ & $\begin{array}{l}\text { Visualizaçōes } \\
2.629 .603 .282\end{array}$ & $\begin{array}{l}\text { Visualizaçōes } \\
\text { 7.834.943.876 }\end{array}$ & $\begin{array}{l}\text { Visualizaçōes } \\
1.288 .544 .093\end{array}$ \\
\hline $\begin{array}{l}\text { Vídeos publicados } \\
362\end{array}$ & $\begin{array}{l}\text { Vídeos publicados } \\
1.644\end{array}$ & $\begin{array}{l}\text { Vídeos publicados } \\
790\end{array}$ & $\begin{array}{l}\text { Vídeos publicados } \\
7.280\end{array}$ & $\begin{array}{l}\text { Vídeos publicados } \\
208\end{array}$ \\
\hline $\begin{array}{l}\text { Data da inscrição } \\
21 / 01 / 2013\end{array}$ & $\begin{array}{l}\text { Data da inscriçäo } \\
15 / 05 / 2006\end{array}$ & $\begin{array}{l}\text { Data da inscrição } \\
01 / 09 / 2013\end{array}$ & $\begin{array}{l}\text { Data da inscrição } \\
12 / 02 / 2012\end{array}$ & $\begin{array}{l}\text { Data da inscrição } \\
07 / 04 / 2011\end{array}$ \\
\hline
\end{tabular}

\begin{tabular}{|c|c|c|c|c|}
\hline Am3nic & $\begin{array}{c}\text { Canal } \\
\text { Nostalgia }\end{array}$ & $\begin{array}{c}\text { Manual do } \\
\text { Mundo }\end{array}$ & $\begin{array}{c}\text { Dani Russo } \\
\text { TV }\end{array}$ & Renato Garcia \\
\hline $\begin{array}{l}\text { Inscritos } \\
12.476 .976\end{array}$ & $\begin{array}{l}\text { Inscritos } \\
11.993 .929\end{array}$ & $\begin{array}{l}\text { Inscritos } \\
11.842 .653\end{array}$ & $\begin{array}{l}\text { Inscritos } \\
11.141 .478\end{array}$ & $\begin{array}{l}\text { Inscritos } \\
10.307 .667\end{array}$ \\
\hline $\begin{array}{l}\text { Visualizaçöes } \\
3.493 .267 .414\end{array}$ & $\begin{array}{l}\text { Visualizaçöes } \\
997.094 .017\end{array}$ & $\begin{array}{l}\text { Visualizaçöes } \\
2.028 .610 .079\end{array}$ & $\begin{array}{l}\text { Visualizaçöes } \\
504.371 .564\end{array}$ & $\begin{array}{l}\text { Visualizaçöes } \\
1.260 .466 .139\end{array}$ \\
\hline $\begin{array}{l}\text { Vídeos publicados } \\
3.907\end{array}$ & $\begin{array}{l}\text { Vídeos publicados } \\
318\end{array}$ & $\begin{array}{l}\text { Vídeos publicados } \\
1.437\end{array}$ & $\begin{array}{l}\text { Vídeos publicados } \\
121\end{array}$ & $\begin{array}{l}\text { Vídeos publicados } \\
1.495\end{array}$ \\
\hline $\begin{array}{l}\text { Data da inscriçäo } \\
\text { 14/12/2012 }\end{array}$ & $\begin{array}{l}\text { Data da inscriçāo } \\
\text { 20/09/2008 }\end{array}$ & $\begin{array}{l}\text { Data da inscriçäo } \\
24 / 07 / 2006\end{array}$ & $\begin{array}{l}\text { Data da inscriçāo } \\
25 / 07 / 2010\end{array}$ & $\begin{array}{l}\text { Data da inscriçäo } \\
29 / 09 / 2011\end{array}$ \\
\hline
\end{tabular}

Figura 1 - Ranking dos canais do YouTube por ordem de inscritos. A figura inclui o número de inscritos, bem como o número de visualizações nos respectivos canais, o número de vídeos já publicados neles e sua data de inscrição Fonte: elaboração dos autores.

Após a identificação dos principais youtubers brasileiros, foram assistidos e classificados os três vídeos mais visualizados de cada respectivo canal. A partir dessa análise, foram identificadas as temáticas: curiosidades $(26,7 \%)$, sexualidade (20\%), competições e desafios $(16,7 \%)$, cultura tecnológica $(13,3 \%)$, relações familiares $(10 \%)$, relacionamentos interpessoais $(6,7 \%)$, conhecimentos gerais $(3,3 \%)$ e vulnerabilidades (3,3\%). Entretanto, para fins deste estudo, foram selecionados os três vídeos mais vistos nas categorias relações familiares, cultura tecnológica e sexualidade, visando à análise e à discussão sobre a saúde mental dos jovens (Quadro 2). 
Reciis - Revista Eletrônica de Comunicação, Informação \& Inovação em Saúde, Rio de Janeiro, v. 15, n. 2, p. 446-462, abr./jun. 2021 [www.reciis.icict.fiocruz.br] e-ISSN 1981-6278

\section{Quadro 2 - Vídeos mais visualizados, separados por temas e número de visualizações}

\begin{tabular}{|l|l|l|l|}
\hline Tema & Canal & Vídeos mais visualizados & Visualizações \\
\hline & Whindersson Nunes & Paródia / haikaiss & 53.975 .338 \\
\hline Cultura tecnológica & Felipe Neto & Rebuliço - paródia despacito & 49.901 .351 \\
\hline & Você Sabia? & 10 pessoas que morreram tirando selfie & 17.382 .906 \\
\hline Relações familiares & Whindersson Nunes & Na sua cara I paródia & 57.619 .038 \\
\hline & Canal Canalha & Pequenas atitudes irritantes de mãe & 17.607 .017 \\
\hline & Dani Russo TV & Apanhei da minha mãe & 13.009 .768 \\
\hline Sexualidade & Dani Russo TV & $\begin{array}{l}\text { Perdi minha virgindade com um cara do } \\
\text { tinder? }\end{array}$ & 19.591 .467 \\
\hline & Canal Canalha & Despedido - Paródia Despacito & 13.589 .233 \\
\hline & Canal Canalha & $\begin{array}{l}\text { Gemidão do zap! Paródia PablloVittar - } \\
\text { K.O. }\end{array}$ & 12.871 .503 \\
\hline
\end{tabular}

Fonte: elaboração dos autores.

A seleção das categorias 'cultura tecnológica', 'relações familiares' e 'sexualidade' emergiram da análise de conteúdo (BARDIN, 2016), caracterizadas como relevantes no que tange à saúde mental do jovem. A categoria cultura tecnológica apresenta vídeos nos quais se percebe a relação do jovem com as tecnologias. Na categoria relações familiares, destacam-se produções que comentam as relações entre os youtubers e seus familiares, em especial pais e mães. Por fim, a categoria sexualidade agrupa vídeos que comentam sobre o comportamento, a iniciação e a vida sexual.

\section{Cultura tecnológica}

Na temática cultura tecnológica, discutiu-se sobre o relacionamento do sujeito com as novas tecnologias. Os três vídeos mais visualizados, somados, totalizam mais de 120 milhões de visualizações, segundo dados coletados em março de 2019: 1) Paródia / Haikaiss com 53.975.338 visualizações; 2) Rebuliço - paródia despacito com 49.901.351; e 3) 10 pessoas que morreram tirando selfie com 17.382.906.

Entende-se que o intenso fluxo de acesso aos vídeos selecionados retrata a vivência atual do adolescente, uma vez que há uma identificação deste com o conteúdo gravado (FRANÇA, 2016). Os jovens utilizam-se das redes sociais online para interagirem com seus pares, e entre eles, ocorre a socialização com os próprios youtubers que, ao compartilharem sua vida, seus interesses e preferências de consumo, criam uma sensação de intimidade com quem assiste aos seus vídeos. Para Marinho (2018), grande parte desse sucesso se deve à familiaridade criada pelos influenciadores digitais, que demonstram ser 'gente como a gente', fomentando a ideia de proximidade e, consequentemente, a admiração do jovem, por se identificar com o personagem/ sujeito do canal (MARINHO, 2018; BENETTI; MENEGALDI; SILVA; MACUCH et al., 2019).

Essa afirmação é corroborada pelo número significativo de vídeos que têm em seu conteúdo narrativas, reais ou fictícias, de situações cotidianas tangentes a questões interpessoais, socioeconômicas, midiáticas, o que aproxima o espectador, haja vista a familiaridade que pode ser estabelecida com o narrador. O mesmo pode ser percebido no vídeo 'Rebuliço' do youtuber Felipe Neto (2017), no qual, ao se referir aos espectadores como família Neto, busca esta relação de proximidade e identificação do jovem com o canal.

Na paródia citada, Felipe Neto divulga as suas ações e os quadros do seu canal, exaltando-o: "tem vídeo todo dia pra te divertir, tem lives maneiras pra gente curtir [...] tem reacts de músicas sensacionais, o 'tente não rir' é engraçado demais e sempre meus cabelos muito coloridos" (NETO, 2017). Com isso, entende-se que o youtuber busca atrair as pessoas para assistirem aos seus outros vídeos, lançando ainda o desafio de 
mudar a cor do seu cabelo a cada um milhão de seguidores, na tentativa de aumentar o interesse dos jovens em segui-lo.

Além disso, o termo rebuliço que intitula a paródia se refere a um gesto realizado por Felipe Neto em vários de seus vídeos, e neste em particular; é possível ver várias pessoas imitando-o, inclusive famosos. O youtuber então convida o espectador a realizar o movimento e, assim, fazer parte desta grande família. Ou seja, ao segui-lo e imitá-lo, o jovem passa a ter a sensação de pertencimento. Na adolescência, em decorrência das inseguranças e incertezas quanto à identidade, o adolescente busca a identificação com o outro, na tentativa de pertencer e ser reconhecido, e o ciberespaço pode proporcionar tal experiência (PRIOSTE, 2016). Contudo, ao participar da vida do sujeito que é famoso, o jovem tende a dedicar seu tempo e energia ao outro, perdendo assim parte das suas vivências e desejos, passando a incorporar conteúdos psíquicos, sem a devida assimilação e compreensão necessária (PRIOSTE, 2016; JERUSALINSK, 2017). Desse modo, utiliza os youtubers como referência para a constituição da sua identidade (BENETTI; MENEGALDI; SILVA; MACUCH et al. 2019).

Em relação ao vídeo '10 pessoas que morreram tirando selfie' (2017), produzido pelo Canal Você Sabia?, traz na descrição da sua página um espaço com várias curiosidades, histórias e fatos curiosos do mundo. No vídeo em questão, os youtubers Lukas Marques e Daniel Molo relatam as histórias de pessoas que morreram ao tentar fazer uma foto de si próprias, o que é usualmente conhecido como selfie. Após contar o fato, ambos comentam e satirizam os acidentes e as pessoas que morreram. Em uma das mortes, na qual uma jovem cai de uma construção, os youtubers chegam a comentar "hoje em dia ninguém sobe aqui, em um lugar alto para dizer [palavrão], meu sonho é ver aquela vista. Não, meu sonho é tirar aquela foto bem top”, o que demonstra a cultura do aparecer, na qual as imagens passam a ser objeto de exibição e admiração, através de comentários, compartilhamentos ou curtidas (EDLER, 2017; SCREMIN; WANZINACK, 2017).

Das selfies e mortes comentadas no vídeo, chama a atenção que apenas três eram adultos; em um dos acidentes, a vítima foi uma criança e, nos restantes, as vítimas eram jovens que se colocaram em situações de risco, em busca da 'foto perfeita'. Sobre isso, Scremin e Wanzinack (2017) afirmam que uma das problemáticas contemporâneas é a exposição excessiva dos jovens nas redes sociais online, e a selfie é um ótimo exemplo disto. O que acontece se deve à impulsividade e à imaturidade cognitiva, que é comum nessa fase do desenvolvimento, mas que contribui para o aumento de comportamentos de risco. Edler (2017) corrobora este entendimento, ao declarar que, por meio da cultura do aparecer, se vive com um excesso de exterioridade, na qual, com o uso das imagens busca-se apenas a admiração alheia (EDLER, 2017; SCREMIN; WANZINACK, 2017). Dessa forma, o estar conectado ultrapassa o desejo de capturar e vivenciar o momento, as imagens e informações passaram a circular com o objetivo de estabelecer relações e buscar o reconhecimento do outro (BRAGA; CARNEIRO; GERMANO, 2017).

Já no vídeo de Whindersson Nunes, percebem-se amplos aspectos referentes ao ambiente virtual e à relação com os jovens. Esse youtuber faz uma paródia da música Haikaiss do RAP LORD (NUNES, 2017b), em que traça um paralelo entre a infância da sua geração e a da atual. No início, ele alega se preocupar com o país, referindo-se às crianças e aos jovens imersos na internet que "não sabem o que é um quintal, vivem numa era virtual"; enquanto isso, no vídeo mostra várias crianças em um parquinho utilizando seus smartphones e sem interagir entre elas ou usufruir dos brinquedos disponíveis no local. Trata-se de uma crítica ao uso excessivo da tecnologia pelos jovens, demonstrando as perdas consequentes de se fazer mais presente no mundo digital ao invés de participar do mundo real, o que pode impactar a saúde e a vida social (KIM; AHN; JEON; LEE, 2012; VAHEDI; SAIPHOO, 2018; ROCKEMBACH; GARRÉ, 2020). Rockembach e Garré (2020) investigaram as modalidades discursivas que vêm constituindo a população jovem, dando ênfase ao YouTube, e entre os vídeos analisados encontra-se Haikaiss. Para os autores, devido à abrangência e ao excesso de utilização, as redes sociais online constituem uma potente estratégia 
de construção de identidade, nas quais, devido à sua conexão constante, os jovens são seduzidos pelo estilo de vida propagado, corroborando a naturalização de seus instrumentos.

A paródia Haikaiss também faz uma diferenciação quanto à forma de resolução dos problemas, uma vez que Whindersson demonstra que, na sua época, eles eram resolvidos por meio da violência, como mostram os trechos seguintes: "já briguei demais meu mano", "se entregasse a galera apanhava quando tu dobrasse ali na esquina", "eu corri, escorreguei, bati a cabeça e não dei um piu, mas o meu amigo riu, dei um murro nele que o dente caiu” e, “da minha mãe levei uma surra pois cheguei sujo da rua”. Já a geração atual, na opinião de Whindersson, não sabe ser criança: "essas crianças de hoje só fogem da luta no quarto", "perdendo a infância, só sendo covarde”, "mas dessa geração eu tenho dó, isso só tende ficar pior, aprendem com a Peppa e Dora aventureira". O youtuber se coloca como oposto a esse comportamento dos mais "jovens" que "fogem da luta no quarto", valorizando uma "cultura antiga" em que "levar surra da mãe" faz parte do aprendizado (NUNES, 2017b).

Entretanto, ao contrário do que o youtuber afirma, a violência ainda existe entre os jovens, sendo apenas reeditada e transferida para o meio virtual. Para Mena (2017), a diferença está no contato físico, pois antigamente a violência ocorria por meio das brigas e necessitava do contato direto, enquanto na era virtual disseminam-se o ódio e a violência por meio do cyberbullying e por esse motivo ocorre sua banalização, pois, na ausência de um corpo, o jovem se sente isento da responsabilidade por seus atos. Oliveira e Ceccarelli (2015) corroboram essa afirmação, ao afirmarem que na internet não existem identidades e sim perfis, podendo-se externar o ódio a alguém ou a uma população por detrás de uma tela, não se comprometendo com as consequências, em decorrência do seu anonimato. Além disso, a violência proferida no ambiente online ultrapassa as fronteiras do tempo, mantendo-se permanentemente presente e podendo potencializar traumas emocionais (XAVIER; CARVALHO; MATEUS; GUERREIRO, 2018).

O vídeo em questão apresenta uma comparação entre as gerações e de suas relações com a tecnologia. Contudo, faz-se necessário a compreensão das tecnologias de informação e comunicação de forma mais ampla, considerando o potencial protetivo e inclusivo que elas podem proporcionar aos jovens, quando utilizadas sem excessos. Para Corso e Corso (2017), em decorrência do individualismo presente na contemporaneidade, as redes sociais online desvelam a insuficiência das relações atuais. Para os autores, enquanto os jovens são percebidos como superficiais, na sua maioria em decorrência da imersão na cibercultura, negligencia-se a possibilidade de que esta seja compreendida como espaço de criação de novas relações e laços sociais. Cabe lembrar que recorrer à internet como meio de autoexpressão, também possibilita a elaboração de conflitos e adversidades, tendo função de elaboração psíquica (ROSA, 2015). Ou seja, a internet pode ser vista tanto como algo que traz prejuízos e riscos aos jovens, quanto como um meio de crescimento e desenvolvimento psíquico e relacional (CORSO; CORSO, 2017). Dessa forma, para que seja bem aproveitada, a fim de contribuir para a vida dos jovens, faz-se necessária sua utilização consciente e acompanhada de adultos que orientem e deem suporte aos adolescentes no meio digital.

\section{Relações familiares}

Os três vídeos selecionados de acordo com a temática de relacionamento familiar abordaram a relação materno-filial. Os vídeos utilizados como exemplos para análise somaram mais de 88 milhões de visualizações, segundo dados levantados em março de 2019 e são: 1) Na sua Cara| Paródia, com 57.619.038 visualizações; 2) Pequenas Atitudes irritantes de mãe, com 17.607.017 e 3) Apanhei da minha mãe, com 13.009.789. Em todas as narrativas, embora usem diferentes estratégias em suas construções, a figura materna aparece cindida em sua totalidade.

Os vídeos selecionados para este estudo retratam a imagem materna estereotipada e polarizada: a mãe má. O primeiro vídeo é de Daniella Russo (2016), e a youtuber relata uma situação real de violência. 
Na circunstância, a mãe da jovem a agrediu fisicamente, ao encontrar um objeto relacionado ao uso de maconha entre seus pertences. No vídeo, Russo afirma que a intenção era enfatizar que "nada se resolve com a violência" e finaliza mostrando o ferimento oriundo da agressão. Nos comentários, usuários da rede afirmam se identificar com a vivência retratada, por meio de comentários como: "[...] minha mãe não é assim, com a sua é tudo é na violência?”, "Dani, eu queria ter você como mãe já que a minha me bate", "eu nem tinha o negócio da maconha e minha mãe simplesmente chegou irritada em casa e me espancou, tô pior mais machucada q suas as pernas [...]" " "minha mãe me bateu pra caralho hj meus braços e costas está igual a perna da dani” (sic) (RUSSO, 2016).

Em contrapartida, Costa (2020), ao analisar a produção audiovisual de um youtuber português, observou na figura central, representada pela mãe, a construção da imagem materna de forma estereotipada e polarizada: a mãe boa. O dono do canal discorre acerca dos poderes de sua mãe, ilustrando-a como alguém que cuida, é solícita aos filhos e organiza o lar, enfatizando a dimensão doméstica e cuidadora.

Essas narrativas demonstram uma perspectiva parcial do objeto, isto é, enfatizam apenas um aspecto da personalidade da genitora - ou boa, ou má (LUCERO; VORCARO, 2018). O que chama a atenção é o fato de que a pesquisa de Costa (2020) também consiste na análise dos vídeos mais assistidos de canais de youtubers, e demonstra a procura e identificação dos jovens portugueses por essa figura materna amorosa. Da mesma forma, a pesquisa de Perez-Torez, Pastor-Ruiz e Abarrou-Ben-Boubaker (2018) avaliou vídeos produzidos por youtubers espanhóis, analisando as representações familiares contidas nos vídeos e observou a valorização dos pais e demonstrações de carinho, respeito e admiração por esses. Enquanto isso, os vídeos com mais visualizações nos canais brasileiros representam, assim como difundem, naturalizam e alimentam a ideia e percepção de uma mãe agressiva e inacessível.

O segundo vídeo, retirado do Canal Canalha, cujo youtuber é Júlio Cocielo, aborda a maternidade de diferentes e delicados modos. Ao longo do vídeo, o youtuber remete às dificuldades no relacionamento com a mãe, retratando diferentes situações em que ela o ofende e age com agressividade, além de apresentar jargões maternos. No contexto da filmagem, apresenta semelhança ao conteúdo do primeiro vídeo, uma vez que em uma das encenações, Cocielo (2017c) simula ter perdido algum objeto e sua mãe diz "se eu for aí e achar eu posso te dar uns tapas?”. Os usuários interagiram com o autor no espaço de comentários dos vídeos: "[...] essa é típica das mães", "minha mãe me bateu só uma vez o resto foi tentativa de assassinato", "é verdade. [...] Isso sempre acontece comigo. Esse vídeo só mostrou a verdade" e "pqp minha mãe era igual a isso (ela continua assim)".

Por fim, o vídeo de Whindersson Nunes (2017a) trata de uma paródia da música 'Na sua cara', no qual a personagem da filha, em busca de alguns objetos perdidos, solicita à mãe que a auxilie na recuperação deles. A personagem materna pronuncia frases que ilustram uma educação punitiva e violenta, dentre elas o jargão "se eu achar se prepara, que eu vou esfregar bem na tua cara". Enquanto isso, encena-se uma perseguição da filha pela mãe, com o objetivo de agredi-la com o referido objeto, encontrado pela genitora. Vale ressaltar que o personagem do pai aparece no vídeo como uma figura pouco relevante e caricata, o qual segue as figuras femininas e tenta proteger a filha, sem sucesso, sendo também agredido pela mãe. Esta parte da narrativa aponta para o lugar dos cuidadores nas configurações familiares, demonstrando uma fragilidade da figura paterna em detrimento de uma mãe autoritária.

Nos três vídeos, é possível visualizar a relação materno-filial representada de forma violenta, contendo a agressividade intrafamiliar como principal questão abordada, da mãe em relação ao filho. Desse modo, fica subentendida a situação de violência representada de forma normalizada, o que é complexo e problemático, uma vez que as mídias sociais online podem interferir na forma como os jovens entendem e lidam com seus desafetos. Segundo Girola (2006), a ameaça de violência provoca um sentimento de perigo, suscitando o desenvolvimento de angústia no adolescente. Além disso, as violências físicas e/ou verbais podem 
comprometer a integridade física e/ou emocional do jovem, desencadeando adoecimento e sofrimento, expressos por tristeza e isolamento social, dificuldades escolares, tendência ao uso de substâncias psicoativas, podendo também favorecer comportamentos de violência, autolesão e suicídio (MAGALHÃES; GOMES; MOTA; CAMPOS et al., 2017). Algumas crianças e adolescentes estão acostumados a viver em contexto de violência, seja ele social ou domiciliar; contudo, é preciso refletir a respeito da importância da propagação da cultura da paz, com o objetivo de romper com os ciclos de violência (HERNANDEZ ARTEAGA; LUNA HERNÁNDEZ; CADENA CHALA, 2017).

\section{Sexualidade}

A temática da sexualidade abordou predominantemente a construção de relacionamentos nas mídias online, a sexualidade feminina e as experiências sexuais online. Os vídeos selecionados somaram mais de 46 milhões de visualizações, sendo eles: 1) Perdi minha virgindade com um cara do tinder? com 19.591.467 visualizações; 2) Despedido - Paródia Despacito com 13.589.233; 3) e Gemidão do Zap! Paródia PablloVittar - K.O com 12.871.503.

O primeiro vídeo trata de uma narrativa sobre como a protagonista perdeu a virgindade com um homem que conheceu pelo aplicativo de relacionamento chamado Tinder (RUSSO, 2017). O Tinder é um aplicativo de localização de pessoas para serviços de relacionamento online; ele se constitui de uma sucessão de perfis pessoais, em que se desliza o dedo para a direita se tiver interessado em conhecer a pessoa ou para a esquerda se não tiver interesse, sendo que se os dois usuários apresentarem mútuo interesse (Match), eles podem iniciar uma conversa (TINDER, c2021). Assim, é possível observar uma mudança na construção de relacionamentos dos jovens, em que o primeiro contato, usualmente surge por meio de sites e aplicativos de relacionamento, como o Tinder, para posteriormente evoluir para as redes sociais, como Instagram e Facebook, apontadas como mais seguras para relacionamentos online, devido à sua maior visibilidade $\mathrm{e}$ confiabilidade (LYKENS; PILLOTON; SILVA; SCHLAMM et al., 2019).

Esse fato foi observado durante a exibição do vídeo 'Perdi minha virgindade com um cara do Tinder?', pois a protagonista relata que após o match, informou seu número de telefone pessoal e iniciaram as trocas de mensagens, que duraram aproximadamente uma semana até marcarem o primeiro encontro. Assim, o acesso dos jovens a aplicativos (apps) de relacionamento pode significar a maior facilidade para ter acesso ao sexo casual e, consequentemente, maior exposição ao risco de contrair infecções sexualmente transmissíveis (ISTs) (QUEIROZ; SOUZA; ARAÚJO; OLIVEIRA et al., 2017). Desta forma, enfatiza-se a importância de ações de educação sexual e disseminação de informações que possam contribuir para a saúde sexual dos jovens, com ações educomunicativas pontuais e contínuas em parceria com profissionais especialistas em sexualidade (TAVARES; MESQUITA, 2020).

Dani Russo relatou também que houve vários encontros antes de iniciar o relacionamento sexual, concluindo sua história com a afirmação de que a "Minha primeira vez foi tranquila, eu fiz com um cara com quem eu me sentia à vontade, com quem eu sentia vontade e na hora em que eu me senti à vontade" (RUSSO, 2017), demonstrando assim autonomia e liberdade na escolha de seu parceiro sexual. Fonseca, Santos, Gessner e Fornari et al. (2018) afirmam que, apesar dessa construção social da maior autonomia e liberdade sexual feminina entre os jovens, as diferenças de gênero impostas pela sociedade ainda determinam suas escolhas sexuais, evidenciando que a iniciação sexual feminina é muito idealizada, no que diz respeito ao momento 'certo', a idade 'certa' e o 'dever' de existir um vínculo duradouro com o parceiro para acontecer, fazendo com que elas convivam diariamente com o progresso e o retrocesso. Diante desse conflito, o ciberespaço pode contribuir para o empoderamento dessas jovens, promovendo mudanças e ressignificando valores, bem como auxiliando no compartilhamento e na difusão de informações e saberes dos desafios coletivos femininos (FERNANDES; SANTOS, 2020). 
O segundo e o terceiro vídeo foram produzidos pelo mesmo protagonista, Júlio Cocielo, responsável pelo Canal Canalha. O segundo vídeo trata de uma paródia, na qual o protagonista relata que foi despedido e busca uma nova oportunidade de emprego de forma exasperada, chegando a relatar que trabalharia como gigolô ou como cantor de funk para "Chamar as patricinha (sic) pra colar aqui no baile" e "ver quando os maloka te enrabarem” (COCIELO, 2017b). Além disso, ele enfatiza o uso de bebidas alcoólicas para incentivar as meninas a ficarem nuas e terem relações sexuais. Nesse vídeo identificamos a propagação de uma prática social chamada de 'cultura do estupro', que consiste em comportamentos sutis ou explícitos que naturalizam a violência contra a mulher, sendo identificada a partir de qualquer tipo de material cultural, desde músicas até pornografia (SOUSA, 2017). Além disso, observa-se a utilização de bebidas alcoólicas como meio para a prática de violência sexual contra a mulher, que é caracterizada como estupro de vulnerável, situação essa identificada em 3,3\% de indivíduos que fazem uso abusivo de álcool episódico e em $6 \%$ das pessoas que possuem transtorno por uso de álcool (MASSARO; ADESSE; LARANJEIRA; CAETANO et al., 2019). Ademais, na paródia se reforça o papel do funkeiro como valorizado, estilo esse conhecido como 'funk ostentação', famoso por seus discursos que remetem à violência sexual e, desta forma, expõe a construção social de relações conflituosas entre os gêneros como normal social (BRILHANTE; GIXIA; BRANCO; VIEIRA et al., 2019). Diante desse cenário de violência de gênero, tendo em conta a proximidade e a identificação que o jovem cria com seu ídolo (BRAYNER, 2014), pode existir uma repetição de padrões e condutas visualizados por eles nos vídeos (NOGARA; MARIANO; VELHO; BORTOLOZZI $e t$ al., 2019). Portanto, a sexualidade e a disseminação da cultura do estrupo em vídeos do YouTube precisam ser melhor estudados.

Já no terceiro vídeo, o protagonista relata uma situação constrangedora, em que ele abre uma mensagem no aplicativo do WhatsApp, contendo um gemido simulando relações sexuais (COCIELO, 2017a). Nesse momento, o personagem relata "Não estou vendo pornô, os cara (sic) aqui do grupo que me enviou", e ainda afirma "Um gemido constrangedor, todo mundo na (sic) minha volta me julgou". Ele finaliza o refrão dizendo "Não sou punheteiro", "vejo pornô? vejo!", "dentro do chuveiro, sujo o chão inteiro, mas só faço essas coisas quando to sozin”. Nesse vídeo, evidenciou-se o compartilhamento de conteúdo e imagens sexuais (sexting). Existem evidências de que o sexting está associado a experiências de vida adversas em jovens de 14 a 17 anos, como também, para as meninas, o sexting pode ser parte de um continuum de vivências sexuais abusivas (TITCHEN; MASLYANSKAYA; SILVER; COUPEY, 2019). De acordo com Maas, Bray e Noll (2019), o compartilhamento de sexting na internet coloca os jovens em uma situação de vulnerabilidade, pois influencia a iniciação precoce da atividade sexual, aumentando o número de parceiros sexuais desprotegidos e o uso de bebidas alcoólicas para estimular relações casuais. Neste sentido, o YouTube pode ser uma ferramenta capaz de proporcionar espaço para a explanação de conteúdos de cunho sexual, promovendo e fazendo com que o jovem compreenda elementos íntimos que teria vergonha de questionar ou sobre os quais se envergonharia de buscar ajuda com profissionais da saúde, possibilitando assim discussões sobre educação sexual (GUL; DIRI, 2019).

\section{CONSIDERAÇÕES FINAIS}

Ao longo da realização deste estudo buscou-se analisar as temáticas abordadas em vídeos produzidos por youtubers brasileiros e abordar suas possíveis implicações no comportamento e na saúde mental de adolescentes. Assim, foram identificadas três temáticas importantes para a compreensão desse complexo fenômeno: a cultura tecnológica, as relações familiares e a sexualidade.

Referente à temática cultura tecnológica, observou-se que a popularidade dos youtubers está diretamente relacionada à proximidade com seu público, visto que os vídeos produzidos apresentam conteúdos de situações cotidianas, fazendo com que o jovem se identifique com o sujeito do canal e busque essa relação 
de proximidade, passando a segui-lo e imitá-lo no processo de formação da sua própria identidade. Já na temática relações familiares, identificou-se que os vídeos retratam a figura materna cindida em sua totalidade, agressiva e inacessível, assim como a violência doméstica vista de forma normalizada, o que pode desencadear sofrimento psicológico nos jovens. Por fim, sobre a sexualidade, foram abordados os novos padrões de relacionamentos, encontros resultantes de aplicativos, bem como a luta feminina por liberdade sexual e os riscos envolvidos no envio e compartilhamento de sexting.

Nota-se a variedade de temáticas a serem exploradas com foco na compreensão das implicações de alguns vídeos produzidos por youtubers na saúde mental de adolescentes. Observa-se também a necessidade de estudos para criação de conteúdos de qualidade em websites, canais do YouTube e redes sociais, que sejam relevantes para a educação dos jovens.

Acredita-se na possibilidade de utilização da internet em benefício das relações sociais e afetivas, das informações de qualidade e, principalmente, da educação. Assim como cabe salientar a necessidade de investimento em educação digital para os jovens e seus responsáveis, de modo a conscientizá-los não só dos riscos provocados por alguns conteúdos que circulam na rede, mas também da utilidade que ela proporciona, e possibilitá-los dialogar a respeito do uso consciente e saudável da tecnologia.

\section{REFERÊNCIAS}

10 PESSOAS que morreram tirando selfie. [S. I.; s. n.], 2017. 1 vídeo (11:58 min). Publicado pelo canal Você Sabia?. Disponível em: https://youtu.be/T-IsL6obdps. Acesso em: 24 maio 2021.

BARDIN, Laurence. Análise de conteúdo. 3. ed. São Paulo: Edições 70, 2016.

BENETTI, Raelly Beatriz Gomes; MENEGALDI, Catherine; SILVA, Camila Cortellete Pereira da; MACUCH, Regiane da Silva et al. Qual a senha do wi-fi? Análise de conteúdo da influência digital na mídia youtube. In: ENCONTRO INTERNACIONAL DE PRODUÇÃO CIENTÍFICA, 11., 29-30 out. 2019, Maringá. Anais Eletrônico do XI EPCC. Maringá: UniCesumar, 2019.

BERNARDAZZI, Rafaela. Youtubers e as relações com a produção audiovisual. In: CONGRESSO BRASILEIRO DE CIÊNCIAS DA COMUNICAÇÃO, 39., 05-09 set. 2016, São Paulo. Anais [...]. São Paulo: Intercom, 2016. Disponível em: https://portalintercom.org.br/anais/nacional2016/resumos/R11-1857-1.pdf. Acesso em: 24 maio 2021.

BRAGA, Vítor; CARNEIRO, Jessica; GERMANO, Idilva Maria. A memória na era dos aplicativos móveis: uma discussão sobre o papel da fotografia em tempos de Snapchat. Rumores, São Paulo, v. 11, n. 21, p. 209-231, 2017. DOI: https://doi.org/10.11606/issn.1982-677X.rum.2017.118199. Disponível em: https://www.revistas. usp.br/Rumores/article/view/118199. Acesso em: 24 maio 2021.

BRASIL. Ministério da Saúde. Secretaria de Atenção à Saúde. Diretrizes nacionais para a atenção integral à saúde de adolescentes e jovens na promoção, proteção e recuperação da saúde. Brasília, DF: Ministério da Saúde, 2010. (Série A. Normas e Manuais Técnicos). Disponível em: https://bvsms.saude.gov.br/ bvs/publicacoes/diretrizes_nacionais_atencao_saude_adolescentes_jovens_promocao_saude.pdf. Acesso em: 24 maio 2021.

BRAYNER, Flávio Henrique Albert. O clichê: notas para uma derrota do pensamento. Por uma consciência ingênua. Educação \& Realidade, Porto Alegre, v. 39, n. 2, p. 557-572, 2014. Disponível em: https://www. scielo.br/j/edreal/a/mycwYTqpV6jWGc8cQDxkG7k/?lang=pt. Acesso em: 24 maio 2021.

BRILHANTE, Aline Veras Morais; GIAXA, Renata Rocha Barreto; BRANCO, July Grassiely de Oliveira; VIEIRA, Luiza Jane Eyre de Souza. Cultura do estupro e violência ostentação: uma análise a partir da artefactualidade do funk. Interface - Comunicação, Saúde, Educação, Botucatu, v. 23, p. e170621, 2019. DOI: https://doi.org/10.1590/Interface.170621. Disponível em: http://www.scielo.br/scielo.php?script=sci arttext\&pid=S1414-32832019000100204\&tIng=pt. Acesso em: 24 maio 2021.

CARVALHO, Bárbara Janiques; PEREIRA, Sara; MARÔPO, Lídia. O hibridismo como estratégia de influência entre uma youtuber portuguesa e seu público jovem. Media e Jornalismo, Lisboa, v. 20, n. 36, p. 41-54, 2020. Disponível em: https://impactum-journals.uc.pt/mj/article/view/2183-5462_36_2. Acesso em: 24 maio 2021. 
Reciis - Revista Eletrônica de Comunicação, Informação \& Inovação em Saúde, Rio de Janeiro, v. 15, n. 2, p. 446-462, abr./jun. 2021 [www.reciis.icict.fiocruz.br] e-ISSN 1981-6278

COCIELO, Júlio. Despedido \& Paródia Despacito. [S. I.; s. n.], 2017a. 1 vídeo (3:48 min). Publicado pelo canal CanalCanalha. Disponível em: https://youtu.be/13tgrCMbQlk. Acesso em: 24 maio 2021.

COCIELO, Júlio. Gemidão do zap! Paródia Pabllo Vittar - K.O. [S. I.; s. n.], 2017b. 1 vídeo (2:50 min). Publicado pelo canal CanalCanalha. Disponível em: https://youtu.be/rp7Qheqy2mQ. Acesso em: 24 maio 2021.

COCIELO, Júlio. Pequenas atitudes irritantes de mãe. [S. I.; s. n.], 2017c. 1 vídeo (9:25 min). Publicado pelo canal CanalCanalha. Disponível em: https://youtu.be/RTHRYQx6U7E. Acesso em: 24 maio 2021.

CORSO, Diana Lichtenstein; CORSO, Mário. Adolescência em cartaz: filmes e psicanálise para entendê-la. São Paulo: Artmed, 2017.

COSTA, Pedro Rodrigues. A presença de arquétipos nos youtubers: modos e estratégias de influência. Galáxia, São Paulo, n. 45, p. 5-19, set.-dez. 2020. DOI: https://doi.org/10.1590/1982-25532020347613. Disponível em: https://www.scielo.br/scielo.php?script=sci arttext\&pid=S1982-25532020000300005\&lng=en\&n rm=iso. Acesso em: 24 maio 2021.

DESLANDES, Suely. Ferreira; COUTINHO, Tiago. O uso intensivo da internet por crianças e adolescentes no contexto da COVID-19 e os riscos para violências autoinflingidas. Ciência \& Saúde Coletiva, Rio de Janeiro, v. 25, n. suppl. p. 2479-2486, jun. 2020. DOI: https://doi.org/10.1590/1413-81232020256.1.11472020. Disponível em: https://scielosp.org/article/csc/2020.v25suppl1/2479-2486/\#. Acesso em: 24 maio 2021.

EDLER, Sandra. Tempos compulsivos: a busca desenfreada pelo prazer. Rio de Janeiro: Casa da Palavra, 2017.

FERNANDES, Terezinha; SANTOS, Edmêa. Ciberfeminismo e multiletramentos críticos na cibercultura. Educar em Revista, Curitiba, v. 36, p. e76124, 2020. DOI: https://doi.org/10.1590/0104-4060.76124. Disponível em: https://www.scielo.br/j/er/a/CCDvRHXmF6TvrzTKxr9RSbd/?lang=pt. Acesso em: 24 maio 2021.

FONSECA, Rosa Maria Godoy Serpa da; SANTOS, Danyelle Leonette Araújo dos; GESSNER, Rafaela; FORNARI, Lucimara Fabiana et al. Gender, sexuality and violence: perception of mobilized adolescents in an online game. Revista Brasileira de Enfermagem, Brasília, DF, v. 71, n. suppl 1, p. 607-614, 2018. DOI: https://doi.org/10.1590/0034-7167-2017-0561. Disponível em: https://www.scielo.br/j/reben/a/BkdzxB44NFkSnx sRHGVs8tB/?lang=en. Acesso em: 24 maio 2021.

FRANÇA, Rafaela Mota Paixão. $O$ adolescente na rede e a rede no adolescente: reflexões sobre as conexões virtuais e suas incidências na subjetividade. Estudos de Psicanálise, Belo Horizonte, n. 45, p. 139-144, jul. 2016. Disponível em: http://pepsic.bvsalud.org/scielo.php?script=sci arttext\&pid=S0100-34372016000100014. Acesso em: 24 maio 2021.

GIROLA, Roberto Guido. Violência e saúde: uma perspectiva psicanalítica. Revista Bioética, Brasília, DF, v. 12, n. 2, p. 99-111, 2006. Disponível em: https://revistabioetica.cfm.org.br/index.php/revista bioetica/article/ view/137. Acesso em: 24 maio 2021.

GOMES, Vinícius Romagnolli Rodrigues. Adolescentes na contemporaneidade: desamparo e laços fragilizados em meio aos ideais da sociedade de consumo. Rio de Janeiro: Gramma, 2018.

GUL, Murat; DIRI, Mehmet Akif. YouTube as a Source of Information About Premature Ejaculation Treatment. The Journal of Sexual Medicine, Malden, v. 16, n. 11, p. 1734-1740, nov. 2019. DOI: https://doi.org/10.1016/j. isxm.2019.08.008. Disponível em: https://pubmed.ncbi.nlm.nih.gov/31522984/. Acesso em: 24 maio 2021.

HERNANDEZ ARTEAGA, Isabel; LUNA HERNÁNDEZ, José Alberto; CADENA CHALA, Martha Cecília. Cultura de Paz: una construcción educativa aporte teórico. Revista Historia de la Educación Latinoamericana, $v$. 19, n. 28, p. 149-172, jun. 2017.

JERUSALINSK, Julieta. A rede nos sustenta no balanço da web? - o sujeito na era das relações virtuais. In: BAPTISTA, Angela; JERUSALINSK, Julieta. (ed.). Intoxicações eletrônicas: o sujeito na era das relações virtuais. Salvador: Editora Ágalma, 2017. p. 13-38.

KIM, Gyu Yong; AHN, Chang Sik; JEON, Hye Won; LEE, Chang Ryeol et al. Effects of the use of smartphones on pain and muscle Fatigue in the upper extremity. Journal of Physical Therapy Science, [s. I.], v. 24, n. 12, p. 1255-1258, 2012. DOI: https://doi.org/10.1589/jpts.24.1255. Disponível em: https://www.jstage.jst.go.jp/ article/jpts/24/12/24 1255/ article/-char/en. Acesso em: 24 maio 2021. 
KNIGHT, Emily; INTZANDT, Brittany; MACDOUGALL, Alicia; SAUNDERS, Travis J. Information seeking in social media: a review of YouTube for sedentary behavior content. Interactive Journal of Medical Research, Toronto, v. 4, n. 1, p. e3, jan. 2015. DOI: https://dx.doi.org/10.2196\%2Fijmr.3835. Disponível em: https://www. ncbi.nlm.nih.gov/pmc/articles/PMC4319070/. Acesso em: 24 maio 2021.

LUCERO, Ariana; VORCARO, Angela Maria Resende. Do objeto parcial ao significante fálico: uma leitura lacaniana de Melanie Klein. Psicologia em Revista, Belo Horizonte, v. 24, n. 3, p. 778-796, set.-dez. 2018. Disponível em: http://pepsic.bvsalud.org/scielo.php?script=sci arttext\&pid=S1677-11682018000300009. Acesso em: 24 maio 2021.

LUPTON, Deborah. Young people's use of digital health technologies in the global north: narrative review. Journal of Medical Internet Research, [s. I.], v. 23, n. 1, p. e18286, jan. 2021. DOI: https://doi. org/10.2196/18286. Disponível em: https://www.jmir.org/2021/1/e18286/. Acesso em: 24 maio 2021.

LYKENS, James, PILLOTON, Molly; SILVA, Cara; SCHLAMM, Emma et al. Google for sexual relationships: mixed-methods study on digital flirting and online dating among adolescent youth and young adults. JMIR Public Health and Surveillance, Toronto, v. 5, n. 2, p. e10695, maio 2019. DOI: https://doi.org/10.2196/10695. Disponível em: https://pubmed.ncbi.nlm.nih.gov/31099335/. Acesso em: 24 maio 2021.

MAAS, Megan K.; BRAY, Bethany C.; NOLL, Jennie G. Online sexual experiences predict subsequent sexual health and victimization outcomes among female adolescents: a latent class analysis. Journal of Youth and Adolescence, Nova lorque, v. 48, n. 5, p. 837-849, maio 2019. DOI: https://doi.org/10.1007/s10964-01900995-3. Disponível em: https://pubmed.ncbi.nlm.nih.gov/30778831/. Acesso em: 24 maio 2021.

MAGALHÃES, Júlia Renata Fernandes de; GOMES, Nadirlene Pereira; MOTA, Rosana Santos; CAMPOS, Luana Moura et al. Intra-family violence: experiences and perceptions of adolescents. Escola Anna Nery Revista de Enfermagem, Rio de Janeiro, v. 21, n. 1, p. e20170003, 2017. DOI: https://doi.org/10.5935/14148145.20170003. Disponível em: https://www.scielo.br/j/ean/a/KnZzNHTkF4TQyrHZb3FSWgw/?lang=en. Acesso em: 24 maio 2021.

MARINHO, Maria Helena. Pesquisa VideoViewers: como os brasileiros estão consumindo vídeos em 2018. In: GOOGLE. Think with Google. [S. I.], set. 2018. Blog. Disponível em: https://www.thinkwithgoogle.com/int// pt-br/estrategias-de-marketing/video/pesquisa-video-viewers-como-os-brasileiros-estao-consumindo-videosem-2018/. Acesso em: 24 maio 2021.

MASSARO, Luciana Teixeira dos Santos; ADESSE, Leila; LARANJEIRA, Ronaldo; CAETANO, Raul et al. Estupros no Brasil e relações com o consumo de álcool: estimativas baseadas em autorrelato sigiloso. Cadernos de Saúde Pública, Rio de Janeiro, v. 35, n. 2, 2019. DOI: https://doi.org/10.1590/0102311X00022118. Disponível em: http://www.scielo.br/scielo.php?script=sci_arttext\&pid=S0102311X2019000205014\&tlng=pt. Acesso em: 24 maio 2021.

MENA, Luiz. O objeto entre o corpo e a inexistência do outro. In: BAPTISTA, Angela; JERUSALINSK, Julieta. (ed.). Intoxicações eletrônicas: o sujeito na era das relações virtuais. Salvador: Editora Ágalma, 2017. p. 211-226.

NETO, Felipe. Rebuliço: paródia Despacito [+10]. [S. I.: s. n.], 2017. 1 vídeo (4:15 min). Publicado pelo canal Felipe Neto. Disponivel em: https://www.youtube.com/watch?v=wzOhKOe4TfU\&ab channel=FelipeNeto. Acesso em: 24 maio 2021.

NOGARA, Michel Andrew; MARIANO, Ederson Fernando; VELHO, Ana Paula Machado; BORTOLOZZI, Flávio et al. Modalidades de expressão dos jovens gamers nas redes sociais digitais. Aletheia, Canoas, v. 52, n. 2, p. 123-134, jul.-dez. 2019. Disponível em: http://pepsic.bvsalud.org/scielo.php?script=sci_arttext\&pid $=$ S1413-03942019000200010. Acesso em: 24 maio 2021.

NUNES, Whindersson. Na sua cara | Paródia Major Lazer - Sua Cara (feat. Anitta \& Pabllo Vittar) (official music video). [s. l.; s. n.], 2017b. 1 vídeo (3:59 min). Publicado pelo canal whinderssonnunes. Disponível em: https://youtu.be/718VjJKOsiU. Acesso em: 24 maio 2021.

NUNES, Whindersson. Paródia / Haikaiss: Rap Lord part Jonas Bento (videoclipe oficial). [s. l.; s. n.], 2017a. 1 vídeo (5:02 min). Publicado pelo canal whinderssonnunes. Disponível em: https://youtu. be/3Zy6ai9jtgY. Acesso em: 24 maio 2021.

OLIVEIRA, Gessé Duque Ferreira de; CECCARELLI, Paulo Roberto. Realidade virtual v. realidade psíquica. Estudos de Psicanálise, Belo Horizonte, n. 44, p. 101-107, dez. 2015. Disponível em: http://pepsic.bvsalud. org/scielo.php?script=sci_arttext\&pid=S0100-34372015000200011. Acesso em: 24 maio 2021. 
PÉREZ-TORRES, Vanesa; PASTOR-RUIZ, Yolanda; ABARROU-BEN-BOUBAKER, Sara. Los youtubers y la construcción de la identidad adolescente. Comunicar: Revista Científica de Educomunicación, [s. I.], n. 55, p. 61-70, 2018. DOI: https://doi.org/10.3916/C55-2018-06. Disponível em: https://recyt.fecyt.es/index.php/ comunicar/article/view/66320. Acesso em: 24 maio 2021.

PRIOSTE, Cláudia. O adolescente e a internet: laços e embaraços no mundo virtual. São Paulo: Edusp, 2016.

QUEIROZ, Artur Acelino Francisco Luz Nunes; SOUZA, Álvaro Francisco Lopes; ARAÚJO; OLIVEIRA, Francisco Braz Milanez et al. A review of risk behaviors for HIV infection by men who have sex with men through geosocial networking phone apps. Journal of the Association of Nurses in AIDS Care, Filadélfia, v. 28, n. 5, p. 807-818, set. 2017. DOI: https://doi.org/10.1016/j.jana.2017.03.009. Disponível em: https://pubmed. ncbi.nlm.nih.gov/28456472l. Acesso em: 24 maio 2021.

RATWATTE, Priyanjali; MATTACOLA, Emily. An exploration of "fitspiration" content on YouTube and its impacts on consumers. Journal of Health Psychology, Londres, v. 26, n. 6, p. 935-946, maio 2019. DOI: https://doi. org/10.1177/1359105319854168. Disponível em: https://pubmed.ncbi.nlm.nih.gov/31190554/. Acesso em: 24 maio 2021.ROCKEMBACH, Guilherme Rego; GARRÉ, Bárbara Hees. O enunciado da juventude digitalizada: youtubers fabricando modos de ser jovem a partir de um dispositivo de juventude. Revista Thema, Pelotas, v. 17, n. 2, p. 449-463, 2020. DOI: https://doi.org/10.15536/thema.V17.2020.449-463.1754. Disponível em: http:// periodicos.ifsul.edu.br/index.php/thema/article/view/1754. Acesso em: 24 maio 2021.

ROSA, Gabriel Artur Marra e. Estetização do self e elaboração psíquica: repercussões das redes sociais na subjetividade. Boletim - Academia Paulista de Psicologia, São Paulo, v. 35, n. 89, p. 424-440, jul. 2015. Disponível em: http://pepsic.bvsalud.org/scielo.php?script=sci_arttext\&pid=S1415-711X2015000200011. Acesso em: 24 maio 2021.

RUSSO, Daniella. Apanhei da minha mãe. [S. I.:, s. n.], 2016. 1 vídeo (4:27 min). Publicado pelo canal Dani Russo Tv. Disponível em: https://youtu.be/l6mJobYCkOY. Acesso em: 24 maio 2021.

RUSSO, Daniella. Perdi minha virgindade com um cara do Tinder?. [S. I.:, s. n.], 2017. 1 vídeo (10:21 min). Publicado pelo canal Dani Russo Tv. Disponível em: https://youtu.be/EclW94B70g4. Acesso em: 24 maio 2021.

SANTOS, Débora de Oliveira Santos; GOMES, Fabíola Alves; TEIXEIRA, Kely Raspante; ROEVER, Leonardo et al. Vulnerabilidade de adolescentes em pesquisa e prática clínica. Revista Bioética, v. 25, n. 1, p. 72-81, 2017. DOI: https://doi.org/10.1590/1983-80422017251168. Disponível em: http://www.scielo.br/j/bioet/a/hHJLcb GbrMSzn5K6rFM5y6q/?lang=pt. Acesso em: 24 maio 2021.

SCREMIN, Sanderson de Freitas; WANZINACK, Clóvis. Sexting: perigos na internet, um estudo de caso com uma amostragem de acadêmicos/as da Universidade Federal do Paraná. Razón y palabra, Quito, v. 21, n. 2, p. 746-761, abr.-jun. 2017. Disponível em: https://www.redalyc.org/articulo.oa?id=199552192039. Acesso em: 24 maio 2021

SOCIAL BLADE. Top 250 youtubers in Brazil sorted by SB rank. [S. I.]: Social Blade LLC, c2018. Disponível em: https://socialblade.com/youtube/top/country/br/mostsubscribed. Acesso em: 21 outubro 2018.

SOUSA, Renata Floriano de. Cultura do estupro: prática e incitação à violência sexual contra mulheres.

Revista Estudos Feministas, Florianópolis, v. 25, n. 1, p. 9-29, jan.-abr. 2017. DOI: https://doi. org/10.1590/1806-9584.2017v25n1p9. Disponivel em: http://www.scielo.br/scielo.php?script=sci arttext\&pid=S0104-026X2017000100009\&Ing=pt\&tlng=pt. Acesso em: 24 maio 2021.

TAVARES, Ronielisson Loiola de Jesus; MESQUITA, Fabiana Elias de Mesquita. Youtubers: potencial de contribuição na educação sexual. Revista online de Política e Gestão Educacional, Araraquara, v. 24, n. 2, p. 554-570, 2020. DOI: https://doi.org/10.22633/rpge.v24i2.13692. Disponível em: https://periodicos.fclar. unesp.br/rpge/article/view/13692. Acesso em: 24 maio 2021.

OS YOUTUBERS brilham na tela dos jovens brasileiros. Mas, e na sua estratégia?. In: GOOGLE. Think with Google. [S. I.], out. 2016. Blog. Disponível em: https://www.thinkwithgoogle.com/int//pt-br/estrategias-demarketing/video/youtubers-brilham-tela-dos-jovens-brasileirol. Acesso em: 24 maio 2021.

TINDER. Então, por que escolher um app de relacionamento como o Tinder?. [S. I.]: Match Group, c2021. Disponível em: https://tinder.com/pt/about-tinder. Acesso em: 26 jan. 2021. 
TITCHEN et al. Sexting and young adolescents: associations with sexual abuse and intimate partner violence. Journal of Pediatric and Adolescent Gynecology, Filadélfia, v. 32, n. 5, p. 481-486, out. 2019. DOI: https:/l doi.org/10.1016/.jpag.2019.07.004. Disponivel em: https://www.sciencedirect.com/science/article/abs/pii/ S108331881930244X. Acesso em: 24 maio 2021.

VAHEDI, Zahra; SAIPHOO, Alyssa. The association between smartphone use, stress, and anxiety: A metaanalytic review. Stress and Health, [s. I.], v. 34, n. 4, p. 1-12, ago. 2018. DOI: https://doi.org/10.1002/smi.2805. Disponível em: https://pubmed.ncbi.nlm.nih.gov/29673047I. Acesso em: 24 maio 2021.

VINGILIS, Elevyn; YILDIRIM-YENIERA, Zümrut; VINGILIS-JAREMKOB, Larissa; SEELEY, Jane et al. Young male drivers' perceptions of and experiences with YouTube videos of risky driving behaviours. Accident Analysis \& Prevention, [s. I.], v. 120, nov. 2018, p. 46-54. DOI: https://doi.org/10.1016/i.aap.2018.07.035. Disponível em: https://www.sciencedirect.com/science/article/abs/pii/S0001457518303804. Acesso em: 24 maio 2021.

YOUTUBERS fazem a cabeça dos jovens. In: GOOGLE. Think with Google. [S. I.], mar. 2016. Blog. Disponível em: https://www.thinkwithgoogle.com/int//pt-br/estrategias-de-marketing/video/youtube-teens/. Acesso em: 24 maio 2021.

XAVIER, Bárbara Moreira; CARVALHO, Beatriz, MATEUS, Inês; GUERREIRO, Maria Catarina; SOUZA, Sidcley Bezerra. Quais os comentários negativos e estratégias de enfrentamento mais comuns e eficazes na plataforma digital Youtube?. Revista @mbienteeducação, São Paulo, v. 11, n. 2, p. 227-239, maio-ago. 2018. DOI: https://doi.org/10.26843/ae19828632v11n22018p228a40. Disponível em: https://publicacoes.unicid.edu. br/index.php/ambienteeducacao/article/view/617. Acesso em: 24 maio 2021. 